\title{
The cut-off value of transient elastography to the value of hepatic venous pressure gradient in alcoholic cirrho- sis
}

Se Ri Ryu', ${ }^{1, *}$ Jeong-Ju Yoo ${ }^{2, *}$, Seong Hee Kang ${ }^{3}$, Soung Won Jeong', Moon Young Kim³ ${ }^{3}$, Young Kyu Cho', Young Chang', Sang Gyune Kim², Jae Young Jang ${ }^{1}$, Young Seok Kim², Soon Koo Baik ${ }^{3}$, Yong Jae Kim ${ }^{4}$, Su Yeon Park ${ }^{5}$, and Baigal Baymbajav ${ }^{6}$

${ }^{1}$ Department of Internal Medicine, Soonchunhyang University Seoul Hospital, Soonchunhyang University College of Medicine, Seoul; 2Department of Internal Medicine, Soonchunhyang University Bucheon Hospital, Soonchunhyang University College of Medicine, Bucheon; ${ }^{3}$ Department of Internal Medicine, Wonju Severance Christian Hospital, Yonsei University Wonju College of Medicine, Wonju; ${ }^{4}$ Department of Radiology, Soonchunhyang University Seoul Hospital, Soonchunhyang University College of Medicine, Seoul; ${ }^{5}$ Department of Biostatistics, Soonchunhyang University Seoul Hospital, Soonchunhyang University College of Medicine, Seoul, Korea; ${ }^{6}$ UB Songdo Hospital, Ulaanbaatar, Mongolia

\section{Graphical Abstract}

Hepatic venous
pressure gradient
measurement
(HVPG)


Background/Aims: The hepatic venous pressure gradient (HVPG) reflects portal hypertension, but its measurement is invasive. Transient elastography (TE) is a noninvasive method for evaluating liver stiffness (LS). We investigated the correlation between the value of LS, LS to platelet ratio (LPR), LS-spleen diameter-to-platelet ratio score (LSPS) and HVPG according to the etiology of cirrhosis, especially focused on alcoholic cirrhosis.

Methods: Between January 2008 and March 2017, 556 patients who underwent HVPG and TE were consecutively enrolled. We evaluated LS, LPR, and LSPS according to the etiology of cirrhosis and analyzed their correlations with HVPG.

Results: The LS value was higher in patients with alcoholic cirrhosis than viral cirrhosis based on the HVPG (43.5 vs. 32.0 $\mathrm{kPa}, P<0.001)$. There were no significant differences in the LPR or LSPS between alcoholic and viral cirrhosis groups, and the areas under the curves for the LPR and LSPS in subgroups according to HVPG levels were not superior to that for LS. In alcoholic cirrhosis, the LS cutoff value for predicting an HVPG $\geq 10 \mathrm{mmHg}$ was $32.2 \mathrm{kPa}$ with positive predictive value (PPV) of $94.5 \%$ and $36.6 \mathrm{kPa}$ for HVPG $\geq 12 \mathrm{mmHg}$ with PPV of $91.0 \%$.

Conclusions: The LS cutoff value should be determined separately for patients with alcoholic and viral cirrhosis. In alcoholic cirrhosis, the LS cutoff values were 32.2 and $36.6 \mathrm{kPa}$ for predicting an HVPG $\geq 10$ and $\geq 12 \mathrm{mmHg}$, respectively. However, there were no significant differences in the LPR or LSPS between alcoholic and viral cirrhosis groups. (Clin Mol Hepatol 2021;27:197-206)

Keywords: Liver cirrhosis; Hypertension, Portal; Elastography

\section{Study Highlights}

The LS value is higher in patients with alcoholic cirrhosis than in those with viral cirrhosis based on HVPG, and the LS cutoff values of alcoholic cirrhosis were 32.2 and $36.6 \mathrm{kPa}$ for predicting an HVPG $\geq 10$ and $\geq 12 \mathrm{mmHg}$, respectively.

\section{INTRODUCTION}

In patients with liver cirrhosis, portal hypertension (PTH) may create complications including variceal bleeding, ascites, and hepatic encephalopathy. The hepatic venous pressure gradient (HVPG) is a measure of PTH that predicts liver fibrosis, the prog- nosis of acute variceal bleeding, the effectiveness of beta-blocker prophylaxis, ${ }^{1-3}$ and the risk for hepatocellular carcinoma. ${ }^{4}$ The HVPG is an important predictor of prognosis in patients with liver cirrhosis; each $1 \mathrm{mmHg}$ increase in the HVPG increases the risk of death by $3 \%{ }^{5}$ However, in a small number of cases, it is difficult to measure the HVPG because of contrast hypersensitivity or un-

\begin{abstract}
Abbreviations:
AUCs, areas under the curves; $\mathrm{Cl}$, confidence interval; CSPH, "clinically significant" portal hypertension; FHVP, free hepatic venous pressure; HBV, hepatitis B virus; HCV, hepatitis C virus; HVPG, hepatic venous pressure gradient; LPR, liver stiffness to platelet ratio; LS, liver stiffness; LSM, liver stiffness measurements; LSPS, liver stiffness-spleen diameter-to-platelet ratio score; NPV, negative predicting value; PPV, positive predictive value; $\mathrm{PTH}$, portal hypertension; $\mathrm{ROC}$, receiver operating characteristic; SPH, "severe" portal hypertension; TE, transient elastography; TIPS, transjugular intrahepatic portosystemic shunt; WHVP, wedge hepatic venous pressure
\end{abstract}

\section{Corresponding author: Soung Won Jeong}

Division of Gastroenterology and Hepatology, Department of Internal Medicine, Soonchunhyang University Seoul Hospital, 59 Daesagwan-ro, Yongsan-gu, Seoul 04401, Korea

Tel: +82-2-710-3076, Fax: +82-2-709-9696

E-mail: jeongsw@schmc.ac.kr

https://orcid.org/0000-0003-2855-6011

\section{Moon Young Kim}

Division of Gastroenterology and Hepatology, Department of Internal Medicine, Wonju Severance Christian Hospital, Yonsei University Wonju College of Medicine, 20 Ilsan-ro, Wonju 26426, Korea

Tel: +82-33-741-1229, Fax: +82-33-745-1228

E-mail:drkimmy@yonsei.ac.kr

https://orcid.org/0000-0002-2501-2206

*These authors contributed equally to this paper. 
derlying cardiopulmonary disease or encephalopathy. In addition, although the frequency of complications is $<1 \%$, these include local pain, a vagal reaction, and transient cardiac arrhythmia, which are associated with low patient acceptance of undergoing this measurement. Recent studies have suggested that liver stiffness measurements (LSM) using transient elastography (TE) reflect liver stiffness (LS), the HVPG value, ${ }^{6,7}$ and the presence of esophageal varices. ${ }^{8}$ Many studies have explored the utility of noninvasive LSM, seeking cutoffs reflecting the HVPG, but few studies have distinguished patients by the etiology of cirrhosis especially alcoholic origin cirrhosis. In addition, the accuracy of LSM is compromised by the total bilirubin level, ${ }^{9-11}$ severe obesity, ${ }^{12}$ and hepatic inflammation. ${ }^{13}$ To overcome the problems associated with HVPG measurement, several studies have sought indices that correlate well with fibrosis status and the HVPG value. The LS-to-platelet ratio (LPR) and the LS-spleen diameter-to-platelet ratio score (LSPS) are useful for staging fibrosis. ${ }^{14-17}$ In this study, we investigated the differences in LSM, LPR, and LSPS according to the etiology of cirrhosis, and calculated LS cutoff values predicting HVPG in patients with alcoholic cirrhosis.

\section{PATIENTS AND METHODS}

\section{Patients}

From January 2008 to March 2017, 556 patients who underwent HVPG and transient TE were consecutively enrolled at three Korean tertiary medical centers. All HVPG and TE tests were performed within 1-month intervals. The indications for patients undergoing HPVG procedure are as follows: 1) predicting the prognosis of patients with a history of varix bleeding or high-risk patients, 2) determination of transjugular intrahepatic portosystemic shunt (TIPS) procedure in varix bleeding or refractory ascites, and 3) determining the therapeutic effect after beta blocker treatment. We excluded patients with noncirrhotic PTH, an unreliable LSM, concomitant extrahepatic malignancy, and a condition that might interfere with LSM, such as active inflammation with a total bilirubin level $>10 \mathrm{mg} / \mathrm{dL}$ and alanine aminotransferase level $>200$ IU/L. Ultimately, 551 patients were analyzed. We recorded, age, sex, liver cirrhosis etiology, baseline laboratory data, and the LSM and LPR. Baseline laboratory data included spleen size and the levels of albumin, bilirubin, platelets, creatinine, aspartate aminotransferase, and alanine aminotransferase. Model for endstage liver disease scores were calculated. Patients were classified as having cirrhosis caused by hepatitis B virus (HBV), hepatitis C virus (HCV), alcohol, mixed etiology, or other etiology (e.g., autoimmune, non-alcoholic fatty liver disease, and cryptogenic causes). HBV patients were positive for hepatitis $B$ virus surface antigen and/or HBV DNA; HCV patients were positive for HCV Ab and/or HCV RNA; and those with alcoholic cirrhosis had ingested $>60 \mathrm{~g}$ alcohol daily (>40 g daily for females) more than three times weekly for $>10$ years. The study protocol was approved by the Institutional Review Boards of Soonchunhyang University Seoul Hospital. The study protocol conformed to the ethical guidelines of the World Medical Association Declaration of Helsinki and was approved by the Institutional Review Board of Soonchunhyang University Seoul Hospital (Number 2020-09005).

\section{HVPG}

The HVPG was measured by professional interventional radiologists in each hospital. The right jugular vein was the most commonly used access route; free hepatic venous pressure (FHVP) was measured after placing a 6-French balloon catheter in the right hepatic vein. The wedge hepatic venous pressure (WHVP) was measured by inflating the balloon catheter in the right hepatic region. HVPG was calculated by subtracting the FHVP from the WHVP. HVPG values were categorized as $\geq 6, \geq 10, \geq 12$, and $\geq 16$ $\mathrm{mmHg}$. An HVPG $\geq 6 \mathrm{mmHg}$ indicates the presence of cirrhosis (21), an HVPG $\geq 10 \mathrm{mmHg}$ indicates an increasing risk for varices and thus is termed "clinically significant" PTH (CSPH) (21), an HVPG $\geq 12 \mathrm{mmHg}$ indicates an increased risk for variceal bleeding and thus is termed "severe" PTH (SPH), and an HVPG $\geq 16 \mathrm{mmHg}$ is an important predictor of poor outcomes, greatly increasing the risk of 1-year mortality $(5,22,23)$.

\section{LSM, LPR, and LSPS}

TE was performed using Fibroscan ${ }^{\circledR} 502$ Touch instruments (Echosens, Paris, France); an interquartile range/median ratio $<30 \%$ and a success rate $>60 \%$ were considered to reflect goodquality data. The LPR was calculated as LS ( $\mathrm{kPa}$ ) / platelet count $\left(10^{9} / \mathrm{L}\right)$ and LSPS was calculated as LS $(\mathrm{kPa}) \times$ spleen diameter $(\mathrm{cm}) /$ platelet count $\left(10^{9} / \mathrm{L}\right)$.

\section{Statistical analyses}

Data were analyzed using the Statistical Package for the Social 


\section{CLINICAL and MOLECULAR}

Volume_27 Number_1 January 2021

Sciences (SPSS) ver. 22.0 for Windows (SPSS, Inc., Chicago, IL, USA). Correlations were sought using Spearman's tests. Receiver operating characteristic (ROC) curves were drawn to explore the utilities of LSM and the LPR in terms of predicting PTH. The optimal LSM and LPR cutoffs were obtained using the Youden index.

\section{RESULTS}

\section{Baseline characteristics}

We analyzed 551 patients with liver cirrhosis. Alcohol was the most common etiology $(334,60.6 \%)$ followed by HBV (127,

Table 1. Baseline characteristics according to etiology (viral vs. alcohol vs. others)

\begin{tabular}{|c|c|c|c|c|c|}
\hline Variable & Total $(n=551)$ & Viral $(n=145)$ & Alcohol $(n=334)$ & Others $(n=72)$ & $P$-value \\
\hline Sex & & & & & $<0.001$ \\
\hline Male & $450(81.7)$ & $95(65.5)$ & $309(92.5)$ & $46(63.9)$ & \\
\hline Female & $101(18.3)$ & $50(34.5)$ & $25(7.5 \%)$ & $26(36.1)$ & \\
\hline Age (years) & $53.3 \pm 9.8$ & $53.5 \pm 9.4$ & $52.7 \pm 9.4$ & $55.9 \pm 11.6$ & 0.033 \\
\hline HVPG (mmHg) & $13.7 \pm 5.2$ & $13.0 \pm 5.3$ & $14.4 \pm 5.0$ & $12.1 \pm 5.7$ & $<0.001$ \\
\hline Fibroscan $^{\circledast}(\mathrm{kPa})$ & $38.4 \pm 22.4$ & $31.8 \pm 20.2$ & $43.5 \pm 22.4$ & $28.1 \pm 19.3$ & $<0.001$ \\
\hline Spleen size (cm) & $12.5 \pm 2.4$ & $13.0 \pm 2.7$ & $12.2 \pm 2.2$ & $12.7 \pm 2.5$ & 0.001 \\
\hline Platelets $\left(10^{3} / \mu \mathrm{L}\right)$ & $111.2 \pm 65.5$ & $91.0 \pm 48.1$ & $123.1 \pm 72.0$ & $96.5 \pm 50.3$ & $<0.001$ \\
\hline Albumin (g/dL) & $3.8 \pm 12.8$ & $3.2 \pm 0.7$ & $3.2 \pm 0.6$ & $7.5 \pm 35.3$ & 0.029 \\
\hline Bilirubin (mg/dL) & $1.5 \pm 1.4$ & $1.2 \pm 1.0$ & $1.7 \pm 1.6$ & $1.4 \pm 1.1$ & 0.001 \\
\hline Creatinine (mg/dL) & $0.8 \pm 0.3$ & $0.8 \pm 0.3$ & $0.8 \pm 0.3$ & $0.8 \pm 0.3$ & 0.436 \\
\hline PT (INR) & $1.3 \pm 0.2$ & $1.3 \pm 0.2$ & $1.3 \pm 0.3$ & $1.3 \pm 0.2$ & 0.665 \\
\hline $\mathrm{Na}$ & $138.3 \pm 3.7$ & $138.8 \pm 3.8$ & $137.9 \pm 3.8$ & $138.9 \pm 3.5$ & 0.026 \\
\hline LPR & $0.5 \pm 0.4$ & $0.5 \pm 0.4$ & $0.5 \pm 0.4$ & $0.4 \pm 0.4$ & 0.201 \\
\hline LSPS & $6.1 \pm 5.7$ & $6.3 \pm 5.6$ & $6.1 \pm 5.6$ & $5.3 \pm 6.5$ & 0.450 \\
\hline AST & $59.9 \pm 40.7$ & $53.0 \pm 36.3$ & $64.1 \pm 43.4$ & $54.4 \pm 33.3$ & 0.011 \\
\hline ALT & $34.8 \pm 28.2$ & $37.9 \pm 29.2$ & $32.4 \pm 26.3$ & $39.7 \pm 33.4$ & 0.041 \\
\hline MELD score & $12.1 \pm 4.3$ & $11.3 \pm 3.4$ & $13.0 \pm 4.8$ & $10.2 \pm 3.2$ & 0.010 \\
\hline
\end{tabular}

Values are presented as mean \pm standard deviation or number (\%).

HVPG, hepatic venous pressure gradient; PT, prothrombin time; INR, international normalized ratio; LPR, liver stiffness to platelet ratio; LSPS, liver stiffnessspleen diameter-to-platelet ratio score; AST, aspartate aminotransferase; ALT, alanine aminotransferase; MELD, model for end-stage liver disease.

Table 2. The comparison of mean values among LSM, LPR, and LSPS index in alcoholic and viral liver cirrhosis patients according to variable HVPG levels

\begin{tabular}{|c|c|c|c|c|c|c|c|c|c|}
\hline \multirow{2}{*}{$\begin{array}{l}\text { HVPG } \\
(\mathrm{mmHg})\end{array}$} & \multicolumn{3}{|c|}{ LSM* $^{*}$} & \multicolumn{3}{|c|}{$\mathrm{LPR}^{+}$} & \multicolumn{3}{|c|}{ LSPS $^{\ddagger}$} \\
\hline & Alcohol & Viral & $P$-value & Alcohol & Viral & $P$-value & Alcohol & Viral & $P$-value \\
\hline$\geq 6$ & 44.38 & 33.09 & $<0.001$ & 0.50 & 0.48 & 0.689 & 6.27 & 6.67 & 0.494 \\
\hline$\geq 10$ & 47.79 & 37.13 & $<0.001$ & 0.54 & 0.56 & 0.647 & 6.78 & 7.76 & 0.125 \\
\hline$\geq 12$ & 51.02 & 39.99 & $<0.001$ & 0.56 & 0.60 & 0.454 & 7.23 & 8.50 & 0.097 \\
\hline$\geq 16$ & 54.00 & 41.65 & $<0.001$ & 0.611 & 0.621 & 0.877 & 7.94 & 8.86 & 0.331 \\
\hline
\end{tabular}

The values shown in the table were all average values. The statistically significant $P$-value was $<0.05$.

LSM, liver stiffness measurements; LPR, liver stiffness to platelet ratio; LSPS, liver stiffness-spleen diameter-to-platelet ratio score; HVPG, hepatic venous pressure gradient.

${ }^{*}$ The unit is $\mathrm{kPa}$.

${ }^{\dagger}$ The unit is $\mathrm{kPa} /$ platelet count $\left(10^{9} / \mathrm{L}\right)$.

${ }^{\ddagger}$ The unit is $\mathrm{LS}(\mathrm{kPa}) \times$ spleen diameter $(\mathrm{cm}) /$ platelet count $\left(10^{9} / \mathrm{L}\right)$. 
$23.0 \%$ ) (Table 1). The causes of cirrhosis were mixed in 32 cases (5.8\%) and other in 39 (7.1\%). Most patients were male (450, $81.7 \%)$, and the mean age was $53.30 \pm 9.76$ years. The mean platelet count was $111.17 \pm 65.53$ cells/L. The mean HVPG value and LSM were $13.73 \pm 5.32 \mathrm{mmHg}$ and $38.43 \pm 22.37 \mathrm{kPa}$, respectively.

\section{Differences in LSM, LPR, and LSPS values according to the etiology of liver cirrhosis}

When we analyzed the LS according to HVPG level $(\geq 6, \geq 10$, $\geq 12$, and $\geq 16 \mathrm{mmHg}$ ), the values were higher in alcoholic cirrhosis
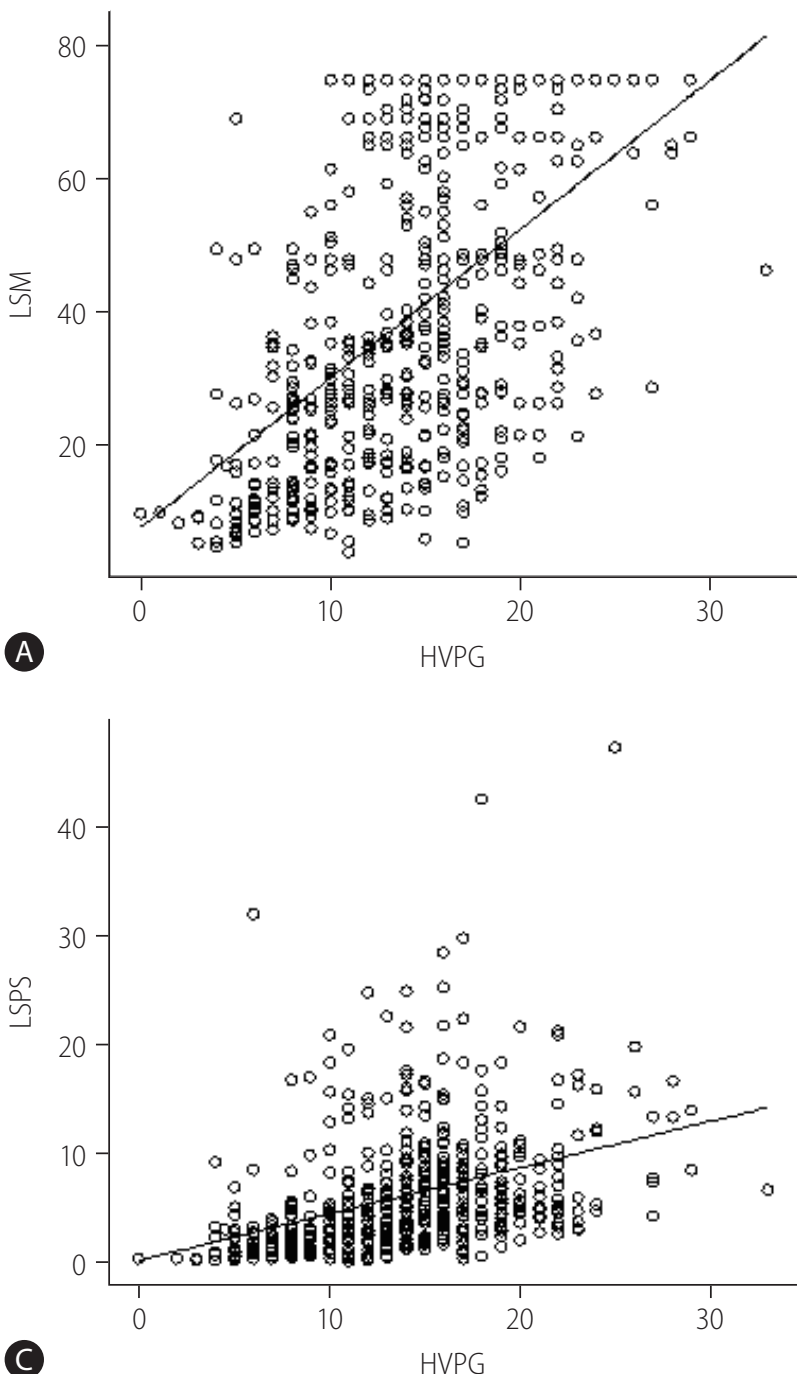

than viral cirrhosis in all HVPG subgroups. However, the LPR and LSPS were not significantly different between alcoholic and viral cirrhosis in any of the HVPG subgroups ( $P=0.689$ and 0.494 at HVPG $\geq 6 \mathrm{mmHg} ; P=0.647$ and 0.125 at HVPG $\geq 10 \mathrm{mmHg}$; $P=0.454$ and 0.097 at HVPG $\geq 12 \mathrm{mmHg}$; and $P=0.877$ and 0.331 at HVPG $\geq 16 \mathrm{mmHg}$ for LPR and LSPS, respectively) (Table 2).

\section{LSM, LPR, and LSPS correlations and diagnostic accuracies for HVPG}

In all patients, the LSM, LPR, and LSPS exhibited good positive correlations with the HVPG (Fig. 1). The correlation coefficients

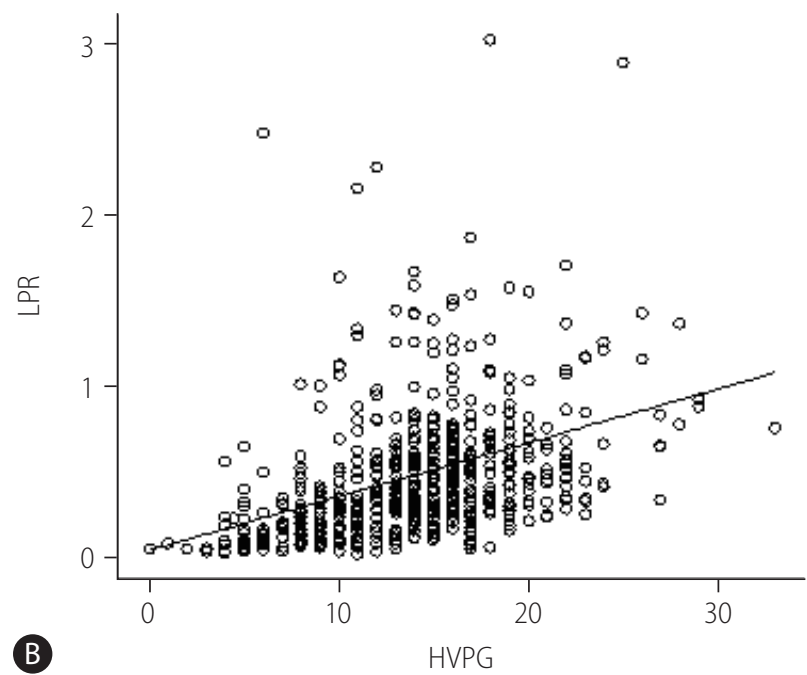

Correlation with HVPG

\begin{tabular}{lcc}
\hline & $\boldsymbol{r}$ & $P$-value \\
\hline (A) LSM & 0.523 & $<0.001$ \\
(B) LPR & 0.410 & $<0.001$ \\
(C) LSPS & 0.390 & $<0.001$ \\
\hline
\end{tabular}

Figure 1. Correlations of the HVPG with LSM, LPR, and LSPS in cirrhosis patients. (A) The correlation between the HVPG and LSM ( $r=0.542, P<0.001)$. (B) The correlation between the HVPG and LPR ( $r=0.537, P<0.001)$. (C) The correlation between the HVPG and LSPS ( $r=0.522, P<0.001)$. LSM, liver stiffness measurements; HVPG, hepatic venous pressure gradient; LPR, liver stiffness to platelet ratio; LSPS, liver stiffness-spleen diameter-to-platelet ratio score. 

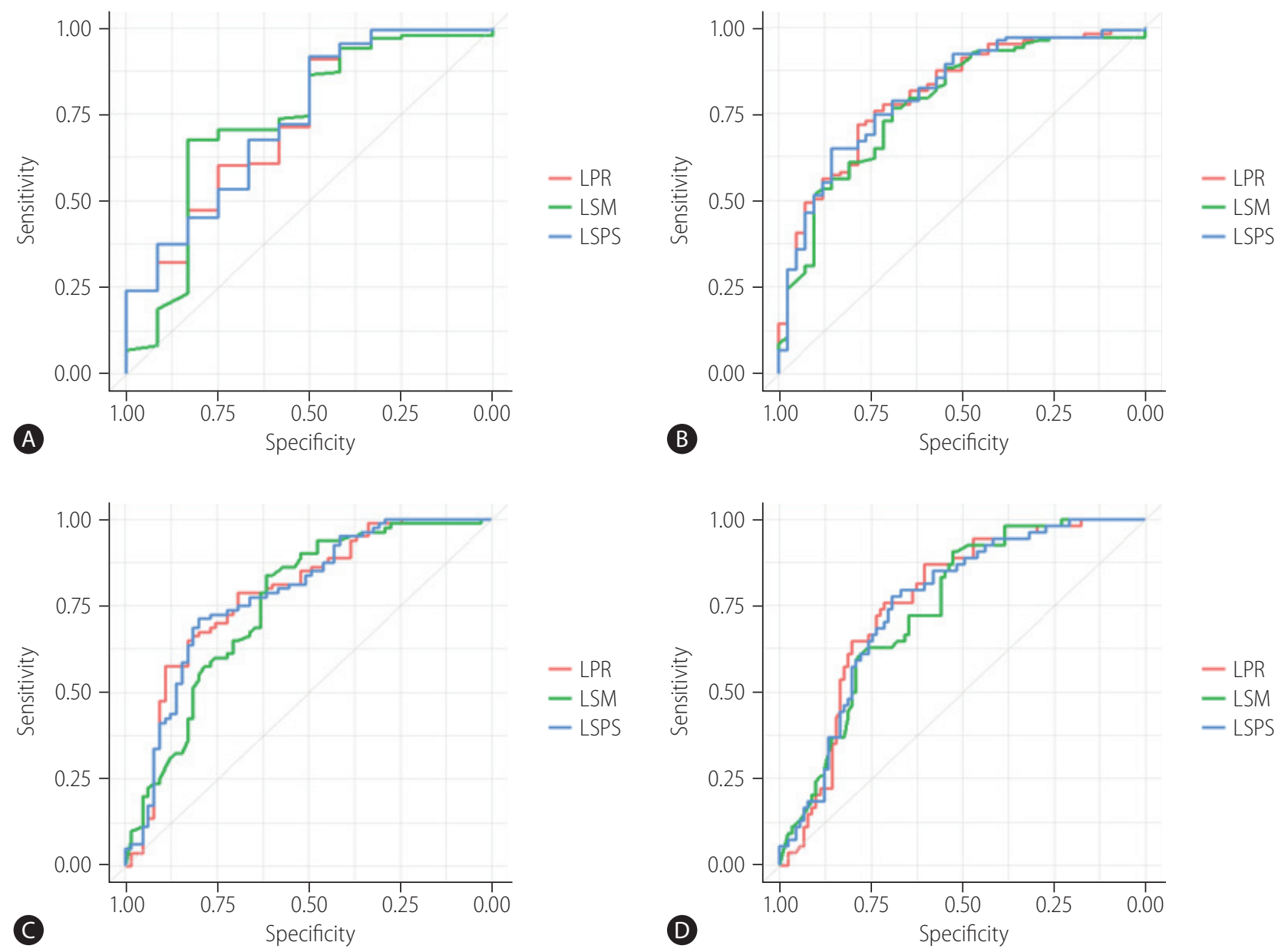

\section{Area under the curve}

\begin{tabular}{lcc}
\hline & AUC & $95 \% \mathbf{C l}$ \\
\hline (A) HVPG $\geq 6$ & & \\
LSM & 0.736 & $(0.560,0.879)$ \\
LPR & 0.733 & $(0.580,0.886)$ \\
LSPS & 0.737 & $(0.604,0.875)$ \\
(B) HVPG $\geq 10$ & & \\
$\quad$ LSM & 0.785 & $(0.723,0.868)$ \\
LPR & 0.811 & $(0.717,0.885)$ \\
LSPS & 0.811 & $(0.755,0.882)$ \\
(C) HVPG $\geq 12$ & & \\
LSM & 0.755 & $(0.666,0.824)$ \\
LPR & 0.786 & $(0.712,0.849)$ \\
LSPS & 0.784 & $(0.702,0.837)$ \\
(D) HVPG $\geq 16$ & & \\
LSM & 0.747 & $(0.690,0.811)$ \\
LPR & 0.765 & $(0.668,0.832)$ \\
LSPS & 0.759 & $(0.702,0.835)$ \\
\hline
\end{tabular}

\section{Comparison of ROC curves}

\begin{tabular}{ccccc}
\hline & AUC1 & AUC2 & Diff. & P-value \\
\hline (A) HVPG $\geq 6$ & & & & \\
LSM vs. LPR & 0.736 & 0.733 & 0.053 & 0.958 \\
LSM vs. LSPS & 0.736 & 0.737 & -0.022 & 0.983 \\
LPR vs. LSPS & 0.733 & 0.737 & -0.223 & 0.823 \\
(B) HVPG $\geq 10$ & & & & \\
LSM vs. LPR & 0.785 & 0.811 & -0.879 & 0.380 \\
LSM vs. LSPS & 0.785 & 0.811 & -0.714 & 0.475 \\
LPR vs. LSPS & 0.811 & 0.811 & 0.000 & 1.000 \\
(C) HVPG $\geq 12$ & & & & \\
LSM vs. LPR & 0.755 & 0.786 & -1.000 & 0.317 \\
LSM vs. LSPS & 0.755 & 0.784 & -0.905 & 0.366 \\
LPR vs. LSPS & 0.786 & 0.784 & 0.197 & 0.844 \\
(D) HVPG $\geq 16$ & & & & \\
LSM vs. LPR & 0.747 & 0.765 & -0.607 & 0.544 \\
LSM vs. LSPS & 0.747 & 0.759 & -0.408 & 0.684 \\
LPR vs. LSPS & 0.765 & 0.759 & 0.415 & 0.678 \\
\hline
\end{tabular}

Figure 2. ROC curves of LSM, LPR, and LSPS for HVPG $\geq 6(A), \geq 10(B), \geq 12(C)$, and $\geq 16 \mathrm{mmHg}(\mathrm{D})$ in all cirrhosis patients. HVPG, hepatic venous pressure gradient; LPR, liver stiffness to platelet ratio; LSM, liver stiffness measurements; LSPS, liver stiffness-spleen diameter-to-platelet ratio score; AUC, areas under the curve; $\mathrm{Cl}$, confidence interval; $\mathrm{ROC}$, receiver operating characteristic; Diff., difference. 
were $0.523(P<0.001)$ for LSM, 0.410 for the LPR $(P<0.001)$, and 0.390 for the LSPS $(P<0.001)$. The diagnostic accuracies of LSM, LPR, and LSPS for HVPG were assessed using ROC curves (Fig. 2). For LSM, the areas under the curves (AUCs) were 0.736 (95\% confidence interval $[\mathrm{CI}], 0.523-0.884 ; P<0.01), 0.785(95 \% \mathrm{Cl}$, $0.716-0.866 ; P<0.01), 0.755(95 \% \mathrm{Cl}, 0.686-0.842 ; P<0.01)$, and $0.747(95 \% \mathrm{Cl}, 0.680-0.827 ; P<0.01)$ for HVPG $\geq 6, \geq 10$, $\geq 12$, and $\geq 16 \mathrm{mmHg}$. For $L P R$, the AUCs were $0.733(95 \% \mathrm{Cl}$, $0.585-0.864 ; P<0.01), 0.811$ (95\% Cl, 0.744-0.861; $P<0.01)$, $0.786(95 \% \mathrm{Cl}, 0.689-0.844 ; P<0.01)$, and $0.765(95 \% \mathrm{Cl}$, $0.685-0.845 ; P<0.01$ ) for HVPG values $\geq 6, \geq 10, \geq 12$, and $\geq 16$ $\mathrm{mmHg}$. For LSPS, the AUCs were $0.737(95 \% \mathrm{Cl}, 0.577-0.894$; $P<0.01)$ for HVPG $\geq 6 \mathrm{mmHg}, 0.811(95 \% \mathrm{Cl}, 0.734-0.880$; $P<0.001)$ for HVPG $\geq 10 \mathrm{mmHg}, 0.784(95 \% \mathrm{Cl}, 0.707-0.855$; $P<0.01)$ for HVPG $\geq 12 \mathrm{mmHg}$, and $0.759(95 \% \mathrm{Cl}, 0.680-0.841$; $P<0.01$ ) for HVPG $\geq 16 \mathrm{mmHg}$. The ROC curves for LSM, LPR, and LSPS had high AUCs but with no significant differences among the three indexes for predicting HVPG $\geq 6 \mathrm{mmHg}$; the LPR and LSPS showed no greater value in predicting HVPG than that of the LSM (Supplementary Table 1). Overall, the AUCs for LSM, LPR, and LSPS decreased with increasing HVPG levels but with no significant differences among the three measures. When subgroup analyses were performed according to the etiology of cirrhosis, patients with alcoholic cirrhosis had same result as above (Supple- mentary Fig. 1). However, in patients with viral cirrhosis, the AUC tended to be higher for LPR and LSPS than for LS at HVPG $\geq 10$ and $\geq 12 \mathrm{mmHg}$ (LSM, LPR, and LSPS: 0.785, 0.811, and 0.811 for HVPG $\geq 10 \mathrm{mmHg} ; 0.755,0.786$, and 0.784 for HVPG $\geq 12 \mathrm{mmHg}$; Supplementary Fig. 2).

\section{LS cutoffs according to the HVPG in patients with alcoholic and viral cirrhosis}

We calculated LS cutoff values in 334 patients with alcoholic cirrhosis (excluding those with viral cirrhosis). The LS optimal cutoffs according to different HVPG levels were calculated using the Youden index. The optimal LS cutoffs for predicting HVPG $\geq 6$, $\geq 10$, and $\geq 12 \mathrm{mmHg}$ were $10.0,32.2$, and $36.6 \mathrm{kPa}$, with a sensitivity, specificity, positive predictive value (PPV), and negative predicting value (NPV) of $98.2 \%, 77.8 \%, 99.4 \%$, and $53.9 \%$ for HVPG $\geq 6 ; 68.1 \%, 80.7 \%, 94.5 \%$, and $34.3 \%$ for HVPG $\geq 10$; and $66.5 \%, 82.4 \%, 91.0 \%$, and $48.1 \%$ for HVPG $\geq 12 \mathrm{mmHg}$, respectively (Table 3). Although the PPV tended to decrease with increasing HVPG, the PPVs of the LS cutoffs for predicting an HVPG $\geq 6$ and $\geq 10$ were relatively high ( $99.4 \%$ and $91.0 \%$, respectively). We also calculated LS cutoff values in 145 patients with viral cirrhosis. The optimal LS cutoffs for predicting HVPG $\geq 10$, and $\geq 12 \mathrm{mmHg}$ were $18.0 \mathrm{kPa}$, respectively with a sensitivity, specific-

Table 3. Comparison of cut-off values in alcoholic, viral, and all etiology of cirrhosis

\begin{tabular}{|c|c|c|c|c|c|}
\hline HVPG (mmHg) & Cut-off (kPa) & Sensitivity (\%) & Specificity (\%) & PPV (\%) & NPV (\%) \\
\hline \multicolumn{6}{|l|}{$\geq 6$} \\
\hline All & 17.9 & 79.7 & 80.7 & 98.6 & 19.2 \\
\hline Alcohol & 10.0 & 98.2 & 77.8 & 99.4 & 53.9 \\
\hline Viral & 18.0 & 67.7 & 83.3 & 97.8 & 18.9 \\
\hline \multicolumn{6}{|l|}{$\geq 10$} \\
\hline All & 27.6 & 71.8 & 78.2 & 91.9 & 44.7 \\
\hline Alcohol & 32.2 & 68.1 & 80.7 & 94.5 & 34.3 \\
\hline Viral & 18.0 & 76.7 & 69.1 & 85.9 & 54.7 \\
\hline \multicolumn{6}{|l|}{$\geq 12$} \\
\hline All & 32.5 & 68.2 & 77.5 & 85.0 & 56.5 \\
\hline Alcohol & 36.6 & 66.5 & 82.4 & 91.0 & 48.1 \\
\hline Viral & 18.0 & 83.8 & 61.5 & 72.8 & 75.5 \\
\hline \multicolumn{6}{|l|}{$\geq 16$} \\
\hline All & 37.2 & 67.2 & 69.9 & 57.4 & 77.9 \\
\hline Alcohol & 45.4 & 70.2 & 68.3 & 59.0 & 78.0 \\
\hline Viral & 18.0 & 90.7 & 52.8 & 53.3 & 90.6 \\
\hline
\end{tabular}

HVPG, hepatic venous pressure gradient; PPV, positive predicting value; NPV, negative predicting value. 
ity, PPV, and NPV of $76.7 \%, 69.1 \%, 85.9 \%$, and $54.7 \%$ for HVPG $\geq 10$; and $83.8 \%, 61.5 \%, 72.8 \%$, and $75.5 \%$ for HVPG $\geq 12$ $\mathrm{mmHg}$, respectively (Table 3). In comparison of cut-off values using LPR and LSPS in patients with alcoholic and all etiology cirrhosis, the LPR cutoffs of all etiology were higher than those of alcohol in each level of HVPG (Supplementary Table 2).

\section{DISCUSSION}

HVPG $\geq 10 \mathrm{mmHg}$ defined as CSPH, has been associated with formation of esophageal varices and poor prognosis, and HVPG $\geq 12 \mathrm{mmHg}$ defined as SPH is related to a higher risk of bleeding from varices. However, HVPG measurement is invasive procedure. Therefore, non-invasive measurement such as TE is required to replace the HVPG measurement.

Good correlations between LSM and HVPG values have been reported in many studies. ${ }^{6,18-21}$ Bureau et al. ${ }^{18}$ measured LS by Fibroscan ${ }^{\circledR}$ in 150 consecutive patients who underwent a liver biopsy with HVPG. Patients were composed of alcohol, viral and other origin. HVPG was correlated with $L S(q=0.858, P<0.001)$ and the LS cut-off value of $21 \mathrm{kPa}$ accurately predicted CSPH in $92 \%$ of the 144 patients for whom LS was successful. Hong et al. ${ }^{21}$ showed a strong positive correlation between LSM and HVPG in the overall population $\left(r^{2}=0.496, P<0.0001\right)$, and reported a CSPH cutoff of $21.95 \mathrm{kPa}$ in their study, which included a higher rate $(61.0 \%)$ of patients with alcoholic cirrhosis compared to other studies. ${ }^{21}$ Vizzutti et al. ${ }^{20}$ evaluated LSM to predict HVPG in 61 consecutive patients with HCV-related chronic liver disease. A strong relationship was found in the overall population ( $r=0.81$, $P<0.0001$ ), and the LSM cutoff values of CSPH and SPH were 13.6 and $17.6 \mathrm{kPa}$, respectively.

The cutoff values for $\mathrm{CSPH}$ determined in previous studies have ranged widely from 13.6 to $24.6 \mathrm{kPa}{ }^{20-26}$ However, most of those studies involved liver diseases of mixed etiologies, and many included more patients with viral cirrhosis than those with alcoholic cirrhosis.

Lemoine et al. ${ }^{19}$ reported that the LSM of patients with alcoholic cirrhosis was higher than that of patients with chronic viral hepatitis. They reported LS cutoffs of $20.5 \mathrm{kPa}$ in $44 \mathrm{HCV}$ cirrhosis patients and $34.9 \mathrm{kPa}$ in 48 alcoholic cirrhosis patients for predicting an HVPG $\geq 10 \mathrm{mmHg} .{ }^{19}$ In our study, the LSM also tended to be higher in patients with alcoholic cirrhosis compared to viral cirrhosis. The LS cutoff value for predicting an HVPG $\geq 10 \mathrm{mmHg}$ in alcoholic cirrhosis, was $32.2 \mathrm{kPa}$ and that of viral cirrhosis was
$18.0 \mathrm{kPa}$.

In alcoholic cirrhosis, the LS value was higher than that of viral cirrhosis. This may be explained by the different spatial distribution of alcoholic fibrosis, which develops in centrilobular and perisinusoidal as well as in periportal regions. ${ }^{27}$ Perisinusoidal fibrosis tends to be more frequent in alcoholics and may increase LSM. ${ }^{28}$ In addition, hepatic alcoholic lesions are also characterized by liver cell necrosis, reactive inflammation, steatosis and pericellular fibrosis or steatohepatitis. ${ }^{29}$ It is possible that steatosis or inflammation may increase $L S$ values as chronic alcoholics progress to cirrhosis. $^{28}$

Some studies have reported that LS combined with the platelet count and spleen size may improve the predictive power of esophageal varices compared to LS alone. $14,30-32$

The difference in LS observed between patients with alcoholic cirrhosis and those with viral cirrhosis was no longer apparent when using the LPR and LSPS indices in this study. However, there were no differences in HVPG diagnostic accuracy, according to the AUC value, among the three indices (LSM, LPR, and LSPS). Comparing with the previous studies, there are two progressed points in this study. First, we analyzed the data of large number of patients based on each classification (HVPG classification as $\geq 6, \geq 10, \geq 12$, and $\geq 16 \mathrm{mmHg}$ ). The number of patients in Lemoine et al.' study ${ }^{19}$ was 92 (44 HCV and 48 alcohol), and that of our study was 551 (145 viral, 334 alcohol, and 72 others). We analyzed each level of HVPG and demonstrated that the cut off value of alcohol group is larger than that of viral group in each level over $10 \mathrm{mmHg}$ of HVPG. We also applied LPR and LSPS whether they can compensate the limitation of LS. Although they did not show the significance, it was a new trial to overcome the limitation of LS. Finally, our study identified the cut off value in each level of HVPG based on large population, and newly applied LS and LSPS to compensate for LS.

According to the Baveno VI recommendations, a LS cutoff of $21 \mathrm{kPa}$ can be used to confirm the presence of $\mathrm{CSPH}_{1}^{18,30}$ but this recommendation was based mostly on studies involving patients with viral cirrhosis..$^{30}$ Our LS cutoff value for predicting CSPH in patients with alcoholic cirrhosis was higher than that of the Baveno VI recommendations (32.2 vs. $21 \mathrm{kPa}$ ). We calculated LS cutoff values exclusively in patients with alcoholic cirrhosis according to the HVPG: $10.0 \mathrm{kPa}$ for HVPG $\geq 6 \mathrm{mmHg}, 32.2 \mathrm{kPa}$ for HVPG $\geq 10$ $\mathrm{mmHg}, 36.6 \mathrm{kPa}$ for HVPG $\geq 12 \mathrm{mmHg}$, and $45.4 \mathrm{kPa}$ for HVPG $\geq 16 \mathrm{mmHg}$. Although the sensitivity and PPV tended to decrease as the HVPG increased, the highest PPVs were associated with $H V P G \geq 6 \mathrm{mmHg}$. 
Although LS is a measure of fibrosis, it may not adequately reflect the HVPG because it is a hemodynamic parameter. ${ }^{20,33}$ In a recent meta-analysis, the measurement of spleen stiffness by ultrasound overcame the limitations associated with LSM, but most of the studies in that analysis evaluated heterogeneous populations, and thus the superiority of spleen stiffness measurement to LSM is not clear. ${ }^{34}$ We expected the LPR and LSPS to overcome the limitations of using LSM, but unfortunately they did not. Further studies are needed on noninvasive methods that do not decrease in diagnostic accuracy with increasing HVPG levels. In this study, we measured HVPG mainly in patients with high risk or prior history of variceal bleeding or in patients requiring TIPS treatment. If the LS cut-off value in our study is externally validated, it can be helpful in determining the clinical treatment direction without invasive HVPG treatment. In particular, we expect TE to replace HVPG in situations such as prognostication of variceal bleeding, further optimization of beta-blocker pharmacotherapy, and determination of hemodynamic effects before and after TIPS procedure.

Our study had some limitations. First, it was a retrospective study. Although HVPG and Fibroscan ${ }^{\circledR}$ measurements were performed on the same day in many patients, there was up to a 1-month interval between measurements in some patients. Second, the length of the spleen was measured using ultrasonography, which cannot accurately detect spleen volume. Third, this study included fewer patients with viral cirrhosis than with alcoholic cirrhosis and did not analyze the viral origins of the cirrhosis. We believe that the LSPS and LPR should be used together to overcome the shortcomings of LSM in patients with viral cirrhosis.

In conclusion, the LS cutoff should be determined separately in patients with alcoholic and viral cirrhosis. In patients with alcoholic cirrhosis, the LS cutoff was $32.2 \mathrm{kPa}$, with a 94.5\% PPV, for diagnosing HVPG $\geq 10 \mathrm{mmHg}$ and $36.6 \mathrm{kPa}$, with a $91.0 \% \mathrm{PPV}$, for diagnosing HVPG $\geq 12 \mathrm{mmHg}$. The LPR and LSPS showed strong correlations with HVPG values $\geq 6 \mathrm{mmHg}$. However, the LPR and LSPS did not show better diagnostic accuracies than that of LS.

\section{Authors' contribution}

Study design: Soung Won Jeong, Moon Young Kim

Acquisition and interpretation of data: Se Ri Ryu, Jeong-Ju Yoo, Seong Hee Kang, Su Yeon Park, Young Kyu Cho, Young Chang

Drafting of the manuscript: Se Ri Ryu, Jeong-Ju Yoo, Soung Won Jeong, Moon Young Kim

Critical revision of the manuscript for important intellectual content: Baigal Baymbajav, Sang Gyune Kim, Jae Young Jang, Young
Seok Kim, Soon Koo Baik, Yong Jae Kim

Statistical analysis: Jeong-Ju Yoo, Se Ri Ryu, Su Yeon Park

\section{Acknowledgements}

This work was supported by the Soonchunhyang University Research Fund and the National Research Foundation of Korea (NRF) grant funded by the Korea government (2020R1F1A1072449, and 2020R1F1A1076282).

\section{Conflicts of Interest}

The authors have no conflicts to disclose.

\section{SUPPLEMENTARY MATERIAL}

Supplementary material is available at Clinical and Molecular Hepatology website (http://www.e-cmh.org).

\section{REFERENCES}

1. Burroughs AK, Groszmann R, Bosch J, Grace N, Garcia-Tsao G, Patch $D$, et al. Assessment of therapeutic benefit of antiviral therapy in chronic hepatitis $C$ : is hepatic venous pressure gradient a better end point? Gut 2002;50:425-427.

2. Burroughs AK, McCormick PA. Natural history and prognosis of variceal bleeding. Baillieres Clin Gastroenterol 1992;6:437-450.

3. D'Amico G, Garcia-Tsao G, Pagliaro L. Natural history and prognostic indicators of survival in cirrhosis: a systematic review of 118 studies. J Hepatol 2006;44:217-231.

4. Ripoll C, Groszmann RJ, Garcia-Tsao G, Bosch J, Grace N, Burroughs $A$, et al. Hepatic venous pressure gradient predicts development of hepatocellular carcinoma independently of severity of cirrhosis. J Hepatol 2009;50:923-928.

5. Said A, Williams J, Holden J, Remington P, Gangnon R, Musat A, et al. Model for end stage liver disease score predicts mortality across a broad spectrum of liver disease. J Hepatol 2004;40:897-903.

6. Carrión JA, Navasa M, Bosch J, Bruguera M, Gilabert R, Forns X. Transient elastography for diagnosis of advanced fibrosis and portal hypertension in patients with hepatitis C recurrence after liver transplantation. Liver Transpl 2006;12:1791-1798.

7. Obara N, Ueno Y, Fukushima K, Nakagome Y, Kakazu E, Kimura 0 , et al. Transient elastography for measurement of liver stiffness measurement can detect early significant hepatic fibrosis in Japanese patients with viral and nonviral liver diseases. J Gastroentero 2008;43:720-728.

8. Li T, Qu Y, Yang B, Xue Y, Wang L. Evaluation of large esophageal 
varices in cirrhotic patients by transient elastography: a metaanalysis. Rev Esp Enferm Dig 2016;108:464-472.

9. Kim SU, Han KH, Park JY, Ahn SH, Chung MJ, Chon CY, et al. Liver stiffness measurement using FibroScan is influenced by serum total bilirubin in acute hepatitis. Liver Int 2009;29:810-815.

10. Sagir A, Erhardt A, Schmitt M, Häussinger D. Transient elastography is unreliable for detection of cirrhosis in patients with acute liver damage. Hepatology 2008;47:592-595.

11. Seo YS, Um SH, Suh SJ, Jung ES, Jang JS, Kwon YD, et al. Changes in liver stiffness during the course of acute hepatitis A. Korean J Hepatol 2008;14:465-473.

12. Wong GL. Update of liver fibrosis and steatosis with transient elastography (fibroscan). Gastroenterol Rep (Oxf) 2013;1:19-26.

13. Zeng X, Xu C, He D, Zhang H, Xia J, Shi D, et al. Influence of hepatic inflammation on FibroScan findings in diagnosing fibrosis in patients with chronic hepatitis B. Ultrasound Med Biol 2015;41:1538-1544.

14. Augustin S, Millán L, González A, Martell M, Gelabert A, Segarra A, et al. Detection of early portal hypertension with routine data and liver stiffness in patients with asymptomatic liver disease: a prospective study. J Hepatol 2014;60:561-569.

15. Berzigotti A, Seijo S, Arena U, Abraldes JG, Vizzutti F, García-Pagán $J C$, et al. Elastography, spleen size, and platelet count identify portal hypertension in patients with compensated cirrhosis. Gastroenterology 2013;144:102-111.e1.

16. Kim BK, Han KH, Park JY, Ahn SH, Kim JK, Paik YH, et al. A liver stiffness measurement-based, noninvasive prediction model for high-risk esophageal varices in B-viral liver cirrhosis. Am J Gastroenterol 2010;105:1382-1390.

17. Okajima A, Sumida Y, Taketani H, Hara T, Seko Y, Ishiba $H$, et al. Liver stiffness measurement to platelet ratio index predicts the stage of liver fibrosis in non-alcoholic fatty liver disease. Hepatol Res 2017:47:721-730.

18. Bureau C, Metivier S, Peron JM, Selves J, Robic MA, Gourraud PA, et al. Transient elastography accurately predicts presence of significant portal hypertension in patients with chronic liver disease. Aliment Pharmacol Ther 2008;27:1261-1268.

19. Lemoine M, Katsahian S, Ziol M, Nahon P, Ganne-Carrie N, Kazemi $\mathrm{F}$, et al. Liver stiffness measurement as a predictive tool of clinically significant portal hypertension in patients with compensated hepatitis C virus or alcohol-related cirrhosis. Aliment Pharmacol Ther 2008;28:1102-1110.

20. Vizzutti F, Arena U, Romanelli RG, Rega L, Foschi M, Colagrande $S$, et al. Liver stiffness measurement predicts severe portal hypertension in patients with HCV-related cirrhosis. Hepatology 2007:45:1290-1297.

21. Hong WK, Kim MY, Baik SK, Shin SY, Kim JM, Kang YS, et al. The usefulness of non-invasive liver stiffness measurements in predicting clinically significant portal hypertension in cirrhotic patients: Korean data. Clin Mol Hepatol 2013;19:370-375.

22. Elkrief $L$, Rautou PE, Ronot M, Lambert S, Dioguardi Burgio M, Fran$\operatorname{coz} C$, et al. Prospective comparison of spleen and liver stiffness by using shear-wave and transient elastography for detection of portal hypertension in cirrhosis. Radiology 2015;275:589-598.

23. Jansen C, Bogs C, Verlinden W, Thiele M, Möller P, Görtzen J, et al. Shear-wave elastography of the liver and spleen identifies clinically significant portal hypertension: a prospective multicentre study. Liver Int 2017;37:396-405.

24. Reiberger T, Ferlitsch A, Payer BA, Pinter M, Schwabl P, Stift J, et al. Noninvasive screening for liver fibrosis and portal hypertension by transient elastography--a large single center experience. Wien Klin Wochenschr 2012;124:395-402.

25. Schwabl P, Bota S, Salzl P, Mandorfer M, Payer BA, Ferlitsch A, et al. New reliability criteria for transient elastography increase the number of accurate measurements for screening of cirrhosis and portal hypertension. Liver Int 2015;35:381-390.

26. Zykus $R$, Jonaitis L, Petrenkienè $V$, Pranculis A, Kupčinskas L. Liver and spleen transient elastography predicts portal hypertension in patients with chronic liver disease: a prospective cohort study. BMC Gastroenterol 2015;15:183.

27. Michalak S, Rousselet MC, Bedossa P, Pilette C, Chappard D, Oberti $F$, et al. Respective roles of porto-septal fibrosis and centrilobular fibrosis in alcoholic liver disease. J Pathol 2003;201:55-62.

28. Coco B, Oliveri F, Maina AM, Ciccorossi P, Sacco R, Colombatto P, et al. Transient elastography: a new surrogate marker of liver fibrosis influenced by major changes of transaminases. J Viral Hepat 2007;14:360-369.

29. Gelsi E, Dainese R, Truchi R, Mariné-Barjoan E, Anty R, Autuori $M$, et al. Effect of detoxification on liver stiffness assessed by Fibroscan $\AA$ in alcoholic patients. Alcohol Clin Exp Res 2011;35:566570.

30. Berzigotti A. Non-invasive evaluation of portal hypertension using ultrasound elastography. J Hepatol 2017;67:399-411.

31. Ding NS, Nguyen $T$, Iser DM, Hong T, Flanagan E, Wong A, et al. Liver stiffness plus platelet count can be used to exclude high-risk oesophageal varices. Liver Int 2016;36:240-245.

32. Takuma Y, Nouso K, Morimoto Y, Tomokuni J, Sahara A, Toshikuni $N$, et al. Measurement of spleen stiffness by acoustic radiation force impulse imaging identifies cirrhotic patients with esophageal varices. Gastroenterology 2013;144:92-101.e2.

33. Ripoll C, Groszmann R, Garcia-Tsao G, Grace N, Burroughs A, Planas $R$, et al. Hepatic venous pressure gradient predicts clinical decompensation in patients with compensated cirrhosis. Gastroenterology 2007;133:481-488.

34. Ma X, Wang L, Wu H, Feng $Y$, Han $X, B u H$, et al. Spleen stiffness is superior to liver stiffness for predicting esophageal varices in chronic liver disease: a meta-analysis. PLoS One 2016;11:e0165786. 